\title{
SELECTED PROBLEMS OF THE MICROSTRUCTURE EVOLUTION DURING MICROALLOYED STEEL WIRE ROD PRODUCTION PROCESS
}

\begin{abstract}
In the present study, we have discussed the selected problems of microstructure development during the whole manufacturing process, i.e. continuous casting, thermomechanical processing, and cold metal forming of the microalloyed steels wires. In the investigated steels, the microstructure development was controlled by the history of deformation and by the effects of microalloying elements, mostly $\mathrm{Nb}$, Ti, and B. It has been concluded that obtained in the ultrafine grained microalloyed steel wires mechanical properties were first of all resulting from specific structural composition and grain refinement. Additionally, it has been proven that austenite grain refinement, that increases nucleation rate during the austenite-to-ferrite phase transformation, as a result of the thermomechanical processing, are very beneficial from point of view of the final mechanical properties. This problem starts to be very important when the microalloyed steel products are subjected to severe plastic deformation, as it has been shown discussed in the present work for combined processes of wire drawing and wire flattening.

Keywords: Continuous casting, thermomechanical processing, AAD, microalloyed steel
\end{abstract}

\section{Introduction}

In the last decades, an implementation of a vast number of new advanced materials can be observed in the global industry. Ultrafine grained steels, especially microalloyed and multiphase steels are used in many applications due to their superior combination of strength and ductility, with increased impact energy absorption [1]. Mechanical properties of these materials are created first of all by the effects of several strengthening mechanisms. One of the most effective strengthening mechanism, i.e. precipitation strengthening is generated by addition of such microalloying elements as $\mathrm{Nb}, \mathrm{Ti}, \mathrm{V}$ or $\mathrm{B}$. It is also very important that the precipitation strengthening, especially due to the strain-induced precipitation of $\mathrm{Nb}(\mathrm{C}, \mathrm{N})$, develops rapidly, what leads to the retardation of the austenite recrystallization, increased ferrite nucleation and further improvement of the mechanical properties of these steels [2]. In the microalloyed steels, microalloying elements, apart from their benefits, cause many difficulties in the manufacturing process. For example, higher reheating temperature of the slabs is required due to the risk of steel clotting during the process of casting. In general, reheating temperature in microalloyed steels should be more carefully controlled, compared to low carbon steels. From one side it should be high enough to ensure complete dissolution of any existing $\mathrm{Nb}(\mathrm{C}, \mathrm{N})$, at the same time should not be too high as dissolution of $\mathrm{TiC}$ and $\mathrm{TiN}$ would lead to abnormal grain growth of austenite phase. Hence, a special care is required during the continuous casting [3]. Because of these problems, the process of continuous casting has to be carried out very carefully, due to special importance of the main process parameters i.e. casting temperature, chemical composition and cooling rate [4-6]. The design process of metal forming of the microalloyed steels should also be carried out with a special thermomechanical control [7-9]. The production process of the ultrafine grained microalloyed steel products is controlled by several metallurgical issues, starting from continuous casting through the thermomechanical hot rolling process, up to the cold severe plastic deformation processes [10]. Hence, the main objective of the current research is to discuss the correlations which can be observed between particular stages of the manufacturing process of the microalloyed steel wires and the microstructural phenomena that occur in the investigated materials during this process.

The present work has been divided into two parts. In the first part, continuous casting and hot rolling processes with controlled cooling have been investigated. The basic idea of this stage of the manufacturing process was how to achieve good mechanical properties of wire bars, especially their ductility, through the microstructure optimization. This goal can be achieved by implementation of the controlled thermomechanical processing where proper process parameters for particular chemical steel composition are carefully designed.

In the second part of the present work, a complex cold metal forming process has been applied to the microalloyed steel in order to study the role of whole history of the microstructure development during the manufacturing process of the steel wires. Finally, the Accumulated Angular Drawing (AAD),

\footnotetext{
* AGH UNIVERSITY OF SCIENCE AND TECHNOLOGY, AL. A. MICKIEWICZA 30, 30-059 KRAKOW, POLAND

\# Corresponding author: mkwiecie@agh.edu.pl
} 
Wire Drawing (WD) and Wire Flattening (WF) processes have been employed to induce SPD effects in the microalloyed steel [11-12]. In this way i.e. using a combination of severe plastic deformation, the workability of the microalloyed steel wire rods has been tested. The AAD process is characterized by a complex history of deformation resulting from various deformation modes. When one compares the AAD processes with the conventional wire drawing, the microstructural effects on the final mechanical properties in the AAD are much more pronounced and attractive from point of view of potential practical implementations. In such complex metal forming process, an attractive combination of mechanical properties was achieved as the results of microstructural inhomogeneity i.e. strong ferrite grain refinement in the surface areas and coarse-grained, more ductile microstructure in the core of the wire. Applied in this stage of metal forming various process parameters allowed one to control the deformation and microstructure inhomogeneities as the results of the accumulated deformation energy, what finally led to controlled grain refinement. The main idea of the manufacturing process of the microalloyed steel wires is presented in the Fig. 1.

The results of the present study support the thesis, that due to an exceptional role of the microstructure development, the improvement of mechanical properties of the final products (of wire drawing and flattening) is hard to be obtained in the case of microalloyed steels. It will be presented that there are significant correlations between each of the stages of microstructure development, starting from the casting process through hot rolling, and finally, cold complex metal forming.

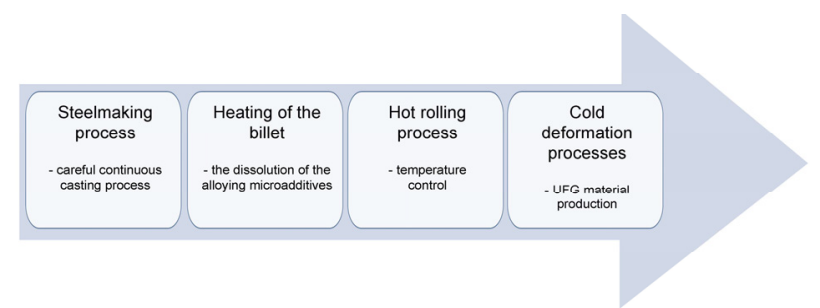

Fig. 1. Schematic representation of the investigation of the microalloyed steel wires manufacturing process

\section{Experimental}

\subsection{Thermomechanical processing}

The aim of the present work is to discuss the result of experimental studies focused on the manufacturing process of the microalloyed steel wires (Table 2), where the strictly controlled number of the microalloying elements requires careful analysis and choice of production parameters in the casting process. In order to produce the high quality casted slabs, several important requirements have to be fulfilled. The first issue is related to a high level of boron what causes clogging in the ladles and hot shortness [13]. Secondly, the microalloying elements should be in solution and the precipitates need to be dissolved and distributed at higher heating temperatures on the beginning of the thermomechanical rolling in order to produce expected effects, i.e. retardation of the austenite static recrystallization, precipitation and solid solution strengthening. For these reasons, carefully controlled chemical composition (including critical amount of boron addition) and properly selected parameters of continuous casting process were used as a casting method for producing high purity charge material in the form of steel billet with dimensions of $100 \times 100 \times 12000 \mathrm{~mm}$. Then, the thermomechanical wire rod rolling was applied which allowed proper control of the microstructure development. Carefully selected deformation parameters, including area reductions, rolling speeds and cooling rates were necessary to control the austenite recrystallization and austenite-to-ferrite phase transformation processes, and finally, the grain refinement in the wires.

In the first stage of the applied thermomechanical processing, the billet was heated for $1 \mathrm{~h} 45 \mathrm{~min}$. in the range of the temperatures: $1180-1200^{\circ} \mathrm{C}$. The rolling process was conducted using 4 rolling mill stands with controlled cooling temperatures. The process parameters were controlled using already installed furnace and rolling line equipment and the results are presented in the Table 1. In the last stage of the thermomechanical processing, before coiling, controlled cooling was performed. The cooling process, with cooling rate of $50^{\circ} \mathrm{C} / \mathrm{s}$, was carried out in water boxes in order to obtain the proper temperature of the phase transformation $\gamma-\alpha$ before coiling. In the last stage of the wire rods production process, coiling with additionally fan cooling was performed. The scheme of the thermomechanical processing is presented in the Fig. 2.

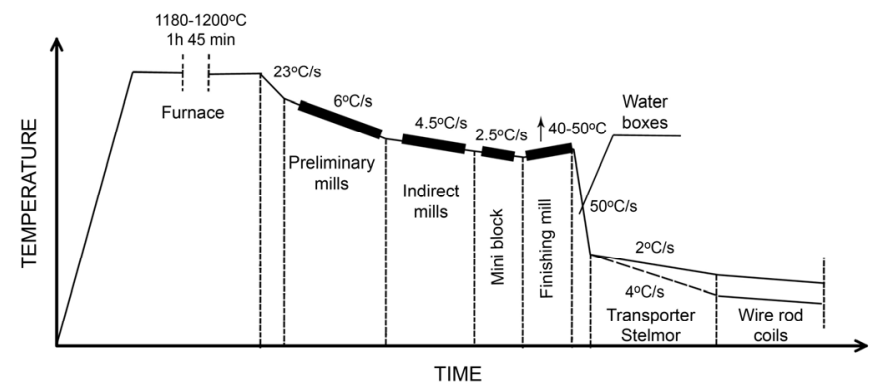

Fig. 2. Process of the thermomechanical wire rods rolling discussed in the present studies

TABLE 1

Temperature during rolling process in the each rolling stage, ${ }^{\circ} \mathrm{C}$

\begin{tabular}{|c|c|c|c|c|c|}
\hline \hline \multicolumn{3}{|c|}{ Temperature measured at different stages of rolling process, ${ }^{\mathbf{0}} \mathbf{C}$} \\
\hline $\begin{array}{c}\text { After the } \\
\text { furnace }\end{array}$ & $\begin{array}{c}\text { After } 7 \text { rolling } \\
\text { stand }\end{array}$ & $\begin{array}{c}\text { Under } \\
\text { the head }\end{array}$ & $\begin{array}{c}\text { Cooling } \\
\text { method }\end{array}$ & \multicolumn{2}{|c|}{ Uncoiling wire rod } \\
\hline 1129 & 985 & 770 & 1 blower & 258 & 370 \\
1132 & 1011 & 780 & fan- the & 240 & 360 \\
1168 & 981 & & last one & 240 & 350 \\
& 1010 & & & & \\
\hline
\end{tabular}

TABLE 2

Chemical composition of casted steel (in wt. \%)

\begin{tabular}{|c|c|c|c|c|c|c|c|c|c|c|}
\hline \hline $\mathbf{C}$ & $\mathbf{M n}$ & $\mathbf{S i}$ & $\mathbf{C u}$ & $\mathbf{N i}$ & $\mathbf{M o}$ & $\mathbf{A l}$ & $\mathbf{N}$ & $\mathbf{T i}$ & $\mathbf{N b}$ & $\mathbf{B}$ \\
\hline 0.07 & 1.36 & 0.27 & 0.16 & 0.08 & 0.02 & 0.020 & 0.0098 & 0.031 & 0.067 & 0.003 \\
\hline
\end{tabular}




\subsection{Cold metal forming processes}

In order to assess the possibilities to perform cold metal forming of the thermomechanically rolled wire rods combined wire drawing (WD) and wire flattening (WF) processes were performed. Firstly, Accumulative Angular Drawing (AAD) process was used to reduce the wire diameters down to $4.0 \mathrm{~mm}$, then wire drawing was applied down to $1.96 \mathrm{~mm}$ in diameter. Finally, wire rods of $1.96 \mathrm{~mm}$ in diameter were flattened in the last stage of the investigated manufacturing process. The AAD, i.e. multi-pass wire drawing process, is a forming process where the high strain accumulation is used as a way to achieve much higher microstructure deformation effects compared to the conventional wire drawing process. Due to design of the AAD process, the high strain accumulation is observed in the surface layers of the wire. It allows one to achieve increased mechanical properties in wires characterized by small diameters [14]. The schematic representation of the investigated manufacturing process is presented in the Fig. 3. The AAD process was performed to reduce the diameter of the wires from $6.5 \mathrm{~mm}$ of the wire rods after hot rolling to the $4.0 \mathrm{~mm}$ (total equivalent strain of 0.96 ). Then, conventional wire drawing process, with 7 passes, was applied. The total equivalent strain obtained in the wire drawing process was 1.43 . In the last stage, 3 passes of the wire flattening were applied, with the total equivalent strain of 0.42 . Wires produced in such a way were deformed with total accumulated equivalent strain of $\varepsilon=2.81$.

In order to characterize the complex microstructure development that was observed during the whole manufacturing process of the microalloyed steel wires, microstructure characterization of the billets was performed on their cross sections after 7 th, 13th and 15 th rolling pass, as well as from the wire rods after coiling and after each of the cold deformation process, i.e. AAD, WD and WF. The microstructures of the specimens were analysed using an optical ZEISS Axio Imager M1m microscope. Additionally, because of the importance of the texture generation in the microstructure development process, especially in severely cold deformed wires, texture measurements were performed using EBSD/SEM technique. The EBSD data was collected using a FEI field emission gun scanning electron microscope (FEGSEM) equipped with a EDAX EBSD camera. TSL software was used for data acquisition, while HKL Channel 5 software package was used for analysis. Assessment of the role of precipitates in the microstructure evolution was performed using TEM investigation of carbon extraction replicas in FEI Tecnai 20 TEM equipped with EDAX EDX spectrometer.

\section{Results and discussion}

\subsection{Continuous casting and thermomechanical processing}

In the present study the thermomechanical processing was investigated simultaneously with the analysis of continuous casting processes, which made it possible to understand and control the microstructure development at each stage of the manufacturing process. In order to verify this statement after each of the characteristic group of the rolling mill, microstructure development was studied. As a result of the continuous casting process the billets with typical defects in both the cross-section and in the longitudinal directions were produced (Fig. 4). The defects observed in the cross section as an effect of the solidification process during continuous casting are presented in the Fig. 4a. It is visible that the discontinuity of the structure composition with characteristic features of the solidification process, what is typical for products of the continuous casting (scratches and cracks) also occurs in the presently investigated material.

In order to analyze the effects of the thermomechanical parameters, on the microstructure development and grain refinement, after each stage of the rolling mill, the slabs and wire rods were systematically examined. In the Fig. 5, the micrographs of the billet after $7^{\text {th }}, 13^{\text {th }}$ and $15^{\text {th }}$ passes are presented. In the case of the specimen after $7^{\text {th }}(40 \times 40 \mathrm{~mm})$ pass (Fig. $\left.5 \mathrm{a}\right)$ it can be observed that perlite colonies are concentrated in several places, while after the next passes (Fig. 5b,c) the refined perlite colonies distribution is more homogeneous in the whole volume of specimens. It can be said that successive deformation causes an increase in the homogeneity of ferrite-pearlite structure. The observed development of the microstructures after each pass of rolling shows that the grain refinement was obtained after each stage of the wire rods rolling and finally the grains size after $15^{\text {th }}$ pass was $15 \mu \mathrm{m}$ in average.

The microstructures produced in the investigated thermomechanical rolling process are more refined than in the typical low carbon steels [15].

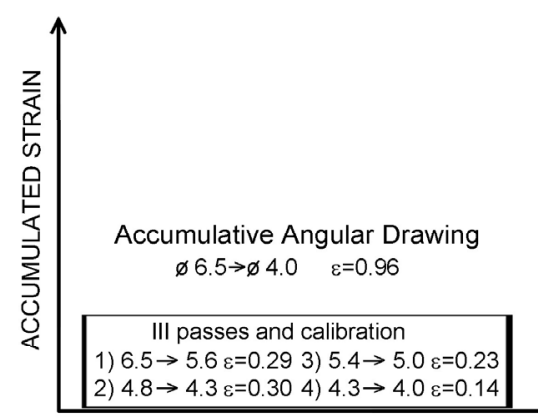

Wire Flattening So $3.01 \rightarrow$ Sk $1.92 \quad \varepsilon=0.42$

Wire Drawing

$\varnothing 4.0 \rightarrow \varnothing 1.96 \quad \varepsilon=1.43$

$\begin{array}{ll}\text { 1) } 4.0 \rightarrow 3.6 \varepsilon=0.21 & \text { 2) } 3.6 \rightarrow 3.2 \varepsilon=0.24\end{array}$

3) $3.2 \rightarrow 2.8 \varepsilon=0.27 \quad$ 4) $2.8 \rightarrow 2.5 \varepsilon=0.23$

5) $2.5 \rightarrow 2.18 \varepsilon=0.27$ 6) $2.18 \rightarrow 1.96 \varepsilon=0.2$
III passes

1) $3.01 \rightarrow 2.69 \varepsilon=0.11$

2) $2.69 \rightarrow 2.42 \varepsilon=0.10$

3) $2.42 \rightarrow 1.92 \varepsilon=0.21$

TIME

Fig 3. The concept of the experimental procedure for the combined of AAD, WD and WF metal forming process 


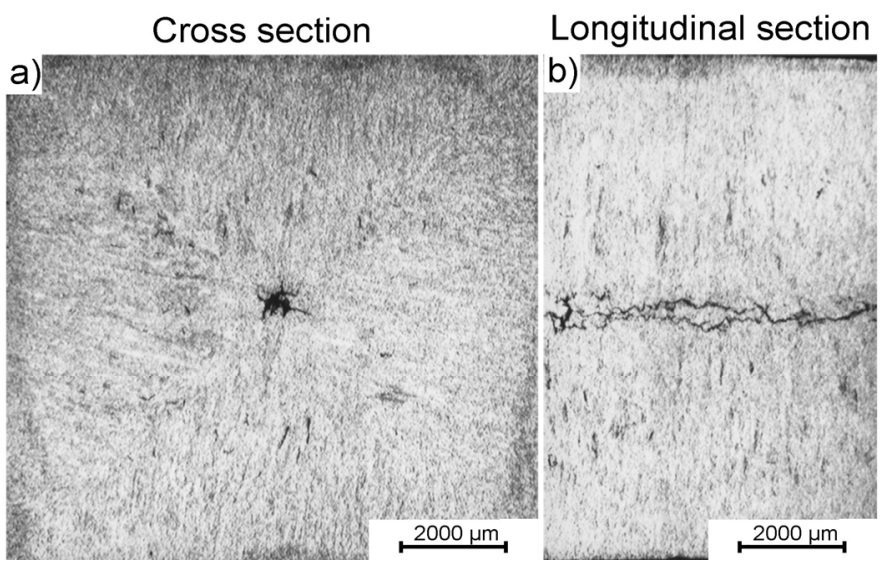

Fig. 4. Billet 1 structures in cross and longitudinal direction obtained by a macro analysis - a), c) and billet 2 microstructure in cross and longitudinal direction $-b)$, d)

The last stage of the hot wire rods rolling was the coiling of the wire rods. The effects of thermomechanical parameters on the microstructure evolution in the final product, i.e. wire rods, are presented in the Fig. 6 . In order to complete the microstructure assessment, the observations were performed both on the cross- and longitudinal-sections of the wires in the center and in the near surface layers of the specimens. Due to the specific relationships between the products of the microalloying (precipitates, solid solution effects) and the microstructure development, the cooling rates applied in the production process also has a significant influence on the structure and the grain refinement observed on the cross section of the wires. Presented micrographs are representative for the obtained microstructure i.e. the polygonal ferrite-bainite structures produced by imple- mentation of high cooling rate. It should be mentioned, that the level of grain refinement has been changed comparing the center of the specimens to the layers near to the surface, what is clearly visible in Fig. 6a,c. The main reason for such microstructural inhomogeneity is the application of high cooling rate during the last stages of the thermomechanical processing. High undercooling of austenite and presence of fine precipitates at the austenite/ferrite interface impede carbon diffusion and change reconstructive type of phase transformation to a displacive type of phase transformation i.e. bainite formation.

Investigated in the present study, microalloyed steel was also examined in detail because of the interrelationships between the grain refinement process and precipitations observed during the thermomechanical processing. As the main strengthening mechanisms that occur in the microalloyed steel are the precipitation and solid solution strengthening, the analysis of precipitates was crucial for the proper analyses of the microstructure development. For that reason, the carbon replicas method was used and the studies were performed on the cross section of wire rods after hot rolling. EDS microanalysis was used for qualitative and quantitative analysis of chemical composition of precipitates. According to the morphology and analysis of EDS, three different types of precipitates are identified: TiC precipitates, strain-induced precipitates of $\mathrm{Nb}(\mathrm{CN})$ and complex precipitates of $(\mathrm{Ti}, \mathrm{Nb}) \mathrm{CN}$. Fig. 7 presents some examples of second phase particles identified in the studied wire rods.

It can be concluded that in the case of microalloyed steels, a significant effect of the ferrite grains refinement is observed due to an increased number of potential nucleation sites generated in a work hardened, unrecrystallized austenite just before the austenite-to-ferrite phase transformation.

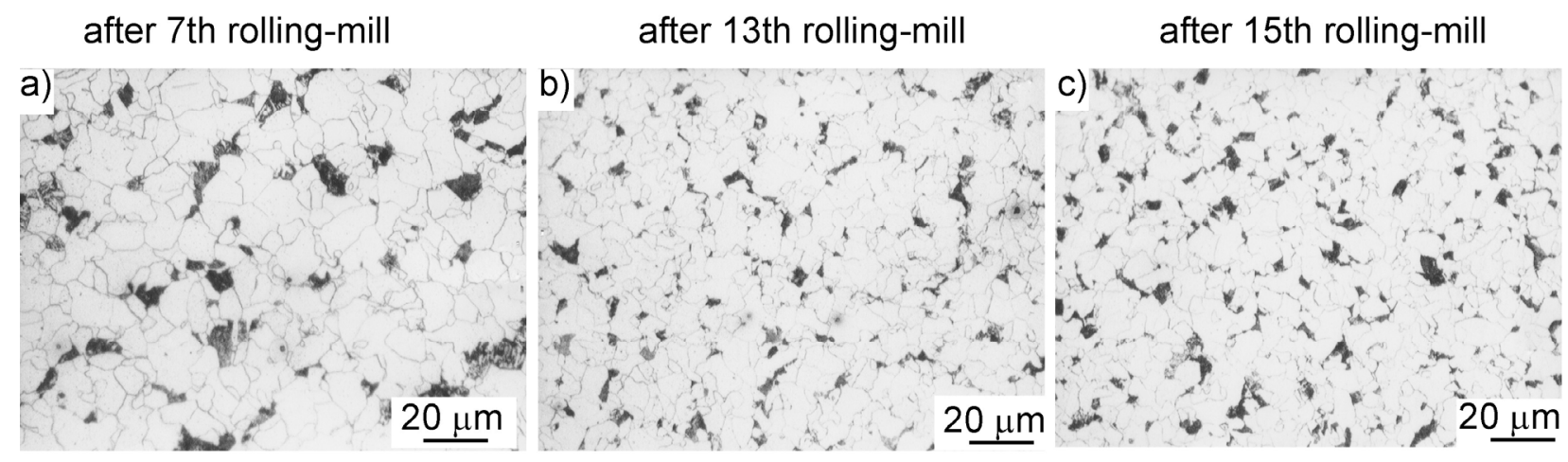

Fig. 5. The microstructure of the billet 1 and 2 after 7th, 13th and 15th rolling mill, light microscopy
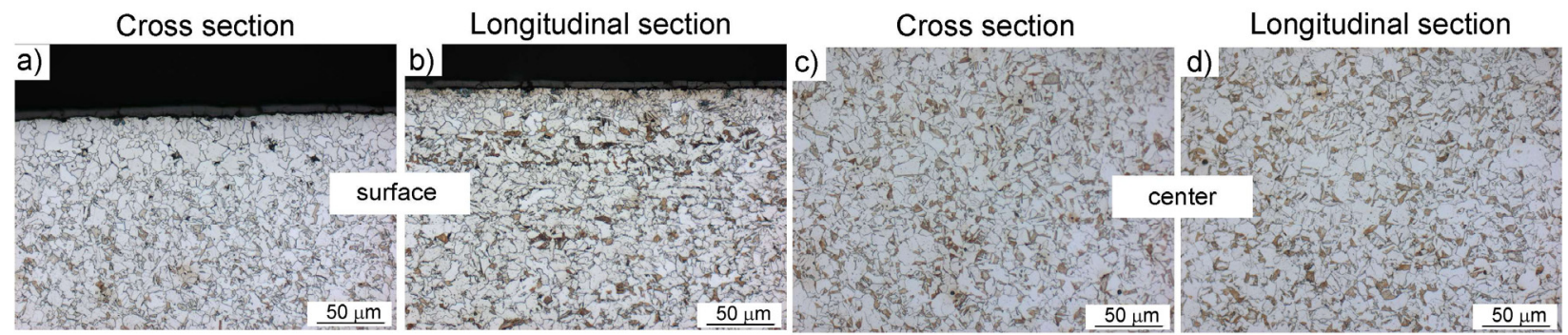

Fig. 6. The wire rods microstructures (light microscopy) 

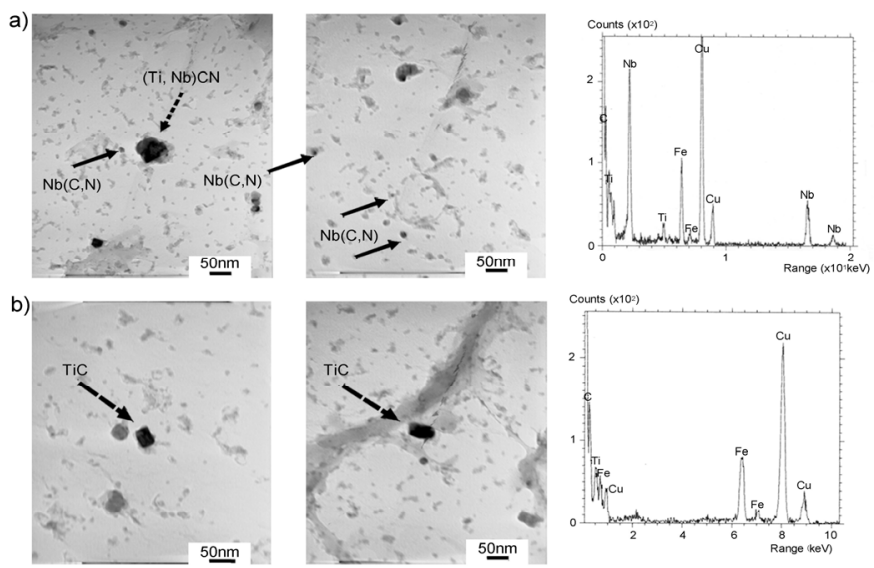

Fig. 7. Examples of precipitates found in microalloyed steel TEM images of replicas and EDS spectra of selected particles. a) - complex compounds $(\mathrm{Ti}, \mathrm{Nb}) \mathrm{CN} ; \mathrm{b})-\mathrm{TiC}$ precipitates [16]

\subsection{Cold wire drawing}

The investigated microalloyed steel after continuous casting and hot wire rods rolling process has been subjected to the study of the ability for further deep cold forming process. In order to asses the workability the AAD, WD and WF processes have been applied. Implemented in the combined cold metal forming, the AAD process, allows one to control the correlations between the process parameters, the strain path and microstructure development that directly affects the mechanical properties of the final products. The microstructures observed in the surface layers are more refined comparing to those in the core of the specimen due to the effects of severly accumulated deformation energy. In the AAD process, these effects are achieved due to the action of four different sources of deformation: bending, torsion, shearing and, typical for wire drawing process, axisymmetrical area reduction. As a direct consequence of applied complex deformation path and due to the controlled inhomogeneity of grain refinement, improved mechanical properties i.e. higher strength and at least preserved ductility can be expected. The specimens after cold metal forming processes are characterized by high mechanical properties. The tensile strength after AAD process reached 985 $\mathrm{MPa}$. Then, in conventional wire drawing process the tensile strength was increased to $1329 \mathrm{MPa}$, and in the last step of forming process, ie. wire flattening, the tensile strength of $1435 \mathrm{MPa}$ was obtained [17]. Such high mechanical properties can only be achieved when the material after continuous casting process is characterized by the homogenous structure in the whole volume.

The results of microstructure characterization of the investigated microalloyed steel wires after AAD process is presented in the (Fig. 8a,c). It can be seen that EBSD analysis enables to reveal the most important features of the deformed microstructures produced in the combined metal forming process. Microstructures of the near surface layers are presented in the (Fig. 8a,b) where inverse pole figures show characterization of the texture changes as an effect of AAD process. Comparison of the grain size and inverse pole figure in the case of the center layers of the specimen (Fig. 8c,d) shows precisely how the applied severe plastic defor- mation affects the microstructure. The highest amount of the accumualted deformation energy caused the grains to be much more refined in the surface area, down to $1-2 \mu \mathrm{m}$, compared the grains in the centre $(5 \mu \mathrm{m})$. The present and previous results [7] confirmed that the strain path applied in the AAD process directly affects the microstructure and texture evolutions in the final product.

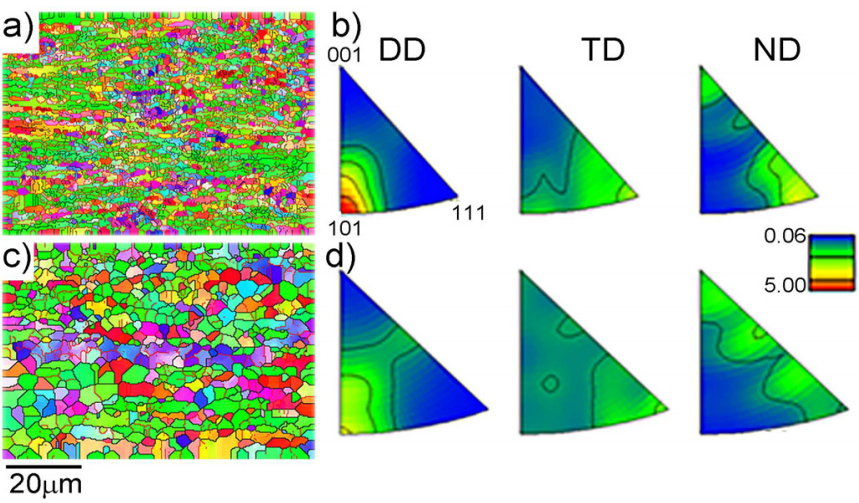

Fig. 8. EBSD results showing IPF maps on the cross section of the studied material obtained after combined continuous casting and AAD processing. Microstructures and measured inverse pole figure taken in the areas close to the surface a), and the center b) of deformed material

The next step of the complex cold deformation process, after the AAD, was the linear conventional wire drawing and reduction of the wire diameter to $1.96 \mathrm{~mm}$. The last operation in the combined metal forming was wire flattening down to $0.4 \mathrm{~mm}$ thickness. The effect of the applied deformation process on the microstructure evolution is presented in Fig. 9. Products obtained in such a way can be considered as multilayered materials because of the clearly seen lamellar structure. Presented in Fig. 9, microstructures show typical elongated grains which correspond to the accumulated energy introduced in the material by severe plastic deformation. The thickness of the elongated grains decreases with the increase of the deformation and the typical lamellar structure is fully developed at a total equivalent strain of about 2.40. The lamellar structure is quite uniformly developed in the AAD+WD+WF specimen (Fig. 9) due to an increase in the total amount of deformation, which finally leads to a decrease of spacing between the lamellar boundaries. The presence of fine second phase particles makes it possible that in some areas irregular lamellar structures were produced.

In general, the presence of fine grains, subgrains, dislocations and precipitates are the most important microstructural elements, which are observed in the severely deformed microalloyed steels. Interpretation of such a complex microstructures compositions can be difficult to be performed using only traditional light, transmission or scanning electron microscopy. The problem can be even more pronounced in the case of microstructure with very fine grain size. The EBSD technique offers a superior quality of grain size, shape and orientation investigation for such complex microstructure analysis and has been used in the present study. An example of the fully developed microstructure of the microalloyed steel after combined SPD process is presented in the Fig. 10. The grains near the surface area (Fig. 10a) are refined 

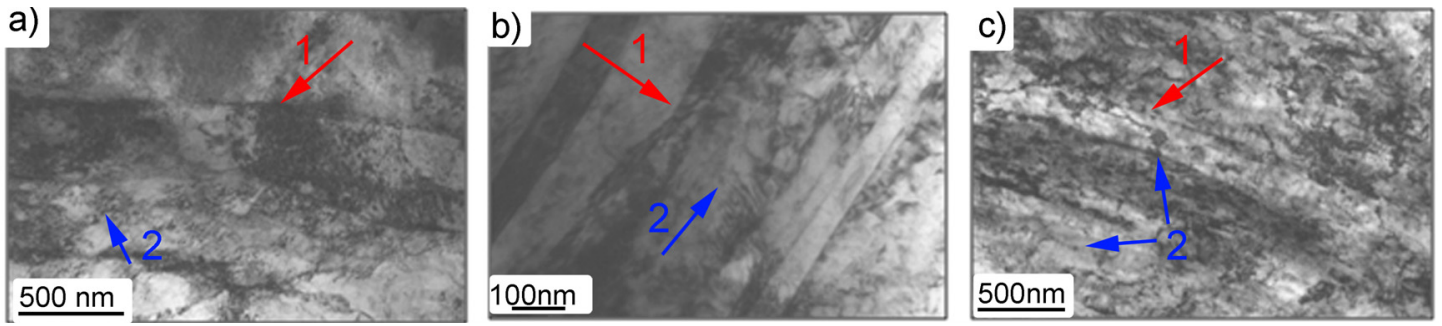

Fig. 9. TEM bright field image of the AAD specimens - a) AAD+WD specimen - b), AAD+WD+WF specimen - c); 1- lamellar structure, 2second phase particles

under $1 \mu \mathrm{m}$ as a direct effect of severe deformation localized in this area, while the average grain size in the ceter of specimen exceded $2 \mu \mathrm{m}$. That leads to the conclusion that the investigated microalloyed steel is susceptible to deep cold metal forming and what is more important, applied combined processing significantly affects the microstructural development both in terms of inhomogenity and refinement.

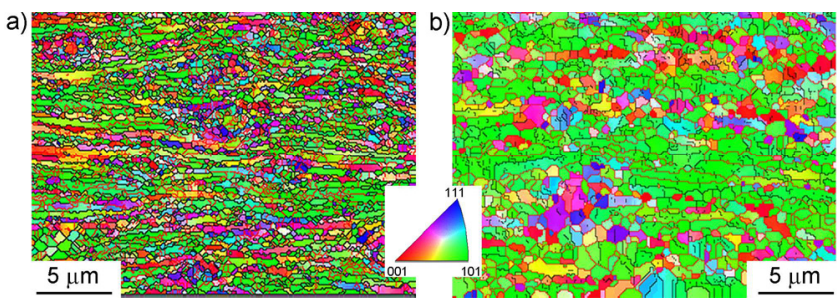

Fig. 10. EBSD results showing the grain refinement of microalloyed steel after complex AAD+WD+WF process. a- area near the surface; b- center of the specimen

\section{Conclusions}

Based on the presented study the following conclusions can be drawn:

- The presented results clearly show that the quality of final products manufactured in the way of deep cold forming, where SPD effects (recrystallization in situ) are observed, is directly linked to the entire production process. The final SPD effects strongly depend on the whole manufacturing process, starting from homogenization of the microstructure and chemical composition in the casting process, through the thermomechanical rolling and finally cold forming i.e. wire drawing and wire flattening.

- Reduction of the amount of B in the chemical composition of the investigated microalloyed steel and properly designed and controlled thermomechanical processing lead to the avoidance of the hot shortness which is often observed in these grades of steels.

- It was documented in the present investigations that additions of the microalloing elements indirectly affect the microstructure development and improve mechanical properties due to the precipitation and solid solution strengthening mechanisms occurring during thermomechanical processing.

- Sufficient workability, represented by the investigated microalloyed steel during combined cold metal forming process, was the result of refined and homogeneous mi- crostructure produced using thermomechanical processing as well as by the presence of a number of strengthening mechanisms, which in consequence delay the occurrence of plastic instability.

\section{Acknowledgment}

The support from the National Science Centre, Poland (grant no. 2013/09/B/ ST8/00141) is greatly appreciated

\section{REFERENCES}

[1] N. Murty, S. Torizuka, Mater. Sci. Forum 633-634, 211-221 (2010).

[2] H.S. Zurob, C.R. Hutchinson, Y. Brechet, G. Purdy, Acta Mater. 50, 3075-3092 (2002).

[3] B. Santillana, D.G. Eskin, R. Boom, L. Katgerman, Mater. Sci. Eng. 27, 1-6 (2011).

[4] A.G Kostryzhev, C.D. Slater, O.O. Marenych, C.L. Davis, Scientific Reports 6 (2016).

[5] J.S. Ha, J.R. Cho, B.Y. Lee, M. Y. Ha, J. Mater. Process. Technol. 113 (1), 257-261 (2001).

[6] K. Miłkowska-Piszczek, J. Falkus, METABK 53, 571-573 (2014).

[7] S. Vervynckta, K. Verbekena, P. Thibauxc, Y. Houbaert, Mater. Sci. Eng. A 528, 5519-5528 (2011).

[8] K. Muszka, D. Dziedzic, Ł. Madej, J. Majta, Mater. Sci. Eng. A 610, 290-296 (2014).

[9] H. Mirzadeh, J.M. Cabrera, J.M. Prado, A. Najafizadeh, Mater. Sci. Eng. A 528, 3876-3882 (2011).

[10] E. López-Martínez, O. Vázquez-Gómez, H.J. Vergara-Hernández, B. Campillo, Int. J. Miner. Metall. Mater. 22, 1304-1312 (2015).

[11] J. Majta, K. Muszka, M. Kwiecień, M. Stefańska-Kądziela, P. Graca, Key. Eng. Mat. 622-623, 249-256 (2014).

[12] K. Muszka, Ł. Madej, J. Majta, Mater. Sci Eng. A574, 68-74 (2013).

[13] C. Nagasaki, M. Kaga, K. Shibata, K. Asakura, M. Hatano, ISIJ International 42, 57-S6, (2002).

[14] M. Wielgus, J. Majta, J. Łuksza, P. Paćko, Steel Res. Int. 81, 490493 (2010).

[15] K. Muszka, P.D. Hodgson, J. Majta, J. Mater. Process. Technol. 177 (1), 456-460 (2006).

[16] K. Muszka, P. Graca, T. Simm, E. Palmiere, Key Eng. Mater. 622-623, 1023-1030 (2014).

[17] J. Majta, K. Muszka, L. Madej, M. Kwiecien, P. Graca, Manufact. Sci. Techn. 3 (4), 134-140 (2015). 